\title{
Familial Ohtahara Syndrome Due to a Novel ARX Gene Mutation
}

\section{Giordano, ${ }^{1 *}$ S. Sartori, ${ }^{2}$ S. Russo, ${ }^{3}$ P. Accorsi, ${ }^{1}$ J. Galli, ${ }^{1}$ A. Tiberti, ${ }^{1}$ E. Bettella, ${ }^{2}$ M. Marchi, ${ }^{3}$ A. Vignoli, ${ }^{4}$ F. Darra, ${ }^{5}$ A. Murgia, ${ }^{2}$ and B. Dalla Bernardina ${ }^{5}$}

${ }^{1}$ Department of Child and Adolescent Neuropsychiatry, Spedali Civili, Brescia, Italy

${ }^{2}$ Department of Pediatrics, University of Padua, Padua, Italy

${ }^{3}$ Molecular Genetics Laboratory, Istituto Auxologico Italiano, Cusano Milanino, Milan, Italy

${ }^{4}$ Epilepsy Center, San Paolo Hospital, Milan, Italy

${ }^{5}$ Child Neuropsychiatry Unit, University of Verona, Verona, Italy

Received 19 August 2009; Accepted 14 July 2010

Recently, it has been reported that longer expansions of the polyalanine tract of the $A R X$ gene could cause an early infantile encephalopathy with suppression burst pattern and that the length of this repeat region could be related to the severity of the electroclinical picture. We describe the history of two male individuals, born from monozygotic twin sisters, with Ohtahara syndrome (OS) that evolved into West syndrome phenotype and epileptic encephalopathy. In both children, we have found a previously unreported missense mutation in exon 5 of $A R X$ gene $(c .1604 T>A)$ resulting in the substitution of a leucine with a glutamine in the aminoacid sequence. The two mothers and the maternal grandmother carry the same mutation which segregates with the disease phenotype in the family. This study confirms that $A R X$ is involved in the pathogenesis of cryptogenic early onset epileptic encephalopathy, such as OS, and suggests that the severity of the electroclinical picture is likely to not exclusively correlate with the extent of expansions of the polyalanine tracts, but rather with the functional effect of different pathogenetic mutations. (c) 2010 Wiley-Liss, Inc.

Key words: $A R X$ gene; EEG; neonatal seizure; infantile spasms; gene expression studies

\section{INTRODUCTION}

Mutations of the Aristaless-related homeobox ( $A R X)$ gene (OMIM *300382) cause a variety of neurological disorders including infantile spasms with or without dystonia or other movement disorders, with or without cerebral malformations [Kato et al., 2004; Guerrini et al., 2007; Poirier et al., 2008]. The genotype-phenotype correlation seems to indicate that malformation phenotypes are caused by protein truncation mutations and missense mutations in the homeobox, whereas nonmalformation phenotypes are associated with missense mutations outside the homeobox and with polyalanine tract expansion [Kato et al., 2007].

Expansions of the first polyalanine tract of the $A R X$ gene are associated with X-linked infantile spasm syndrome and epileptic

\section{How to Cite this Article:}

Giordano L, Sartori S, Russo S, Accorsi P, Galli J. ,Tiberti A, Bettella E, Marchi M, Vignoli A, Darra F, Murgia A, Bernardina BD. 2010. Familial Ohtahara syndrome due to a novel $A R X$ gene mutation.

Am J Med Genet Part A 152A:3133-3137.

dyskinetic encephalopathy [Stromme et al., 2002; Turner et al., 2002; Kato and Dobyns, 2005; Guerrini et al., 2007]. Longer expansions of the same polyalanine tract have been recently reported as a cause of early infantile epileptic encephalopathy with suppression burst pattern (Ohtahara syndrome; OS) without brain malformations and a possible relationship between the length of this repeat region and the severity of the epileptic phenotype has been suggested [Kato et al., 2003, 2007].

To further support the possible causative relationship between $A R X$ gene mutations and OS, we report two related male individuals with OS that evolved into West syndrome phenotype and subsequently into an epileptic encephalopathy with polymorphic and refractory seizures, who carry a previously unreported missense mutations in exon five of $A R X$ gene.

\section{CLINICAL REPORTS}

The two boys we report on were born to two monozygotic twin sisters and both had a neonatal-onset encephalopathy. A maternal uncle, who died at 2 years of age during a prolonged status

${ }^{\star}$ Correspondence to:

L. Giordano, M.D., Piazzale Spedali Civili, no. 1, Brescia 25030, Italy.

E-mail: pafivan@libero.it

Published online 24 November 2010 in Wiley Online Library

(wileyonlinelibrary.com)

DOI 10.1002/ajmg.a.33701 


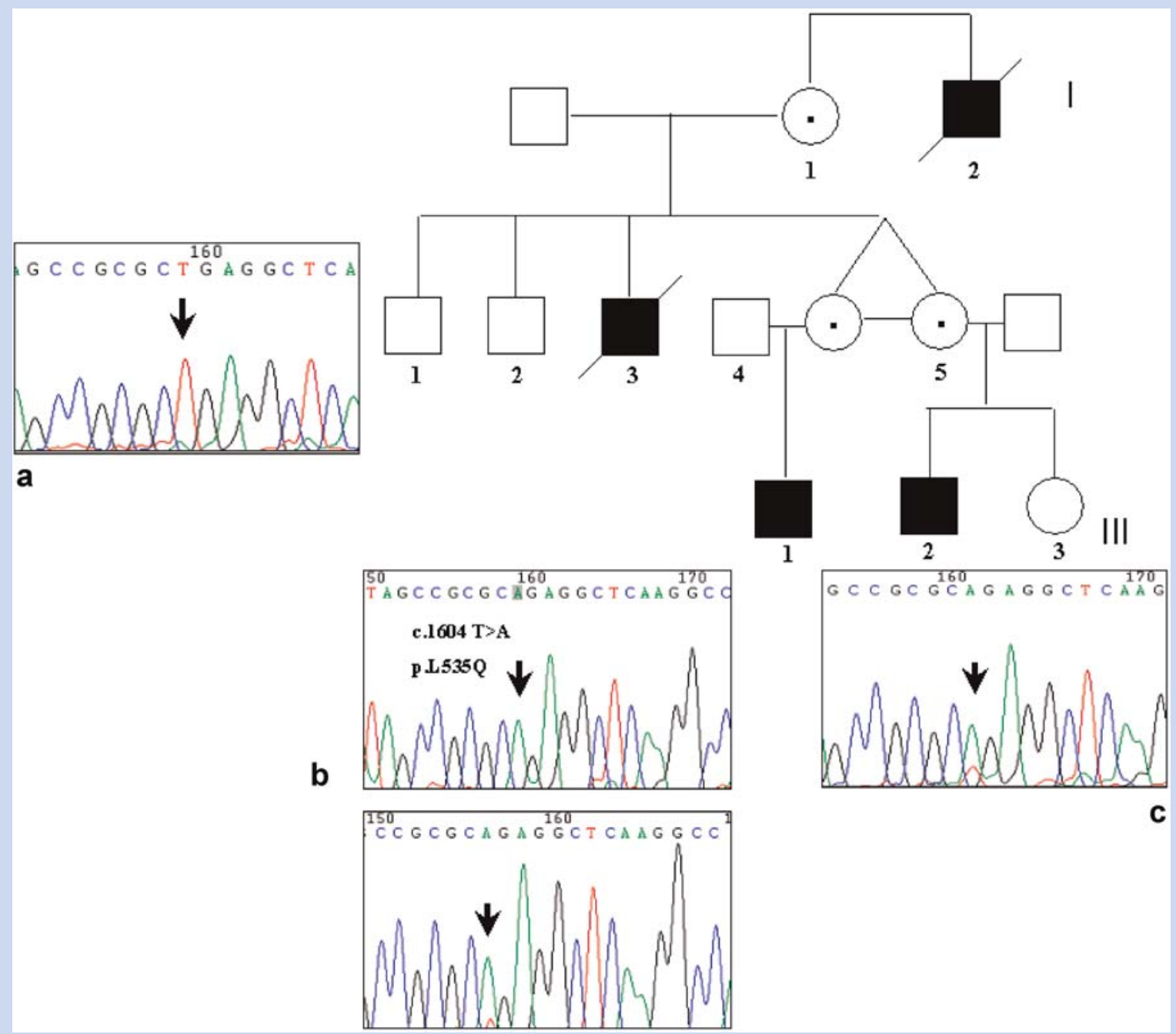

FIG. 1. Family pedigree. Pedigree shows four affected probands on three different generations: in (a) a wild-type sequence is reported; in (b) genomic sequence carrying the mutation and CDNA, below, sequence are shown; in (c) sequence of heterozygous mother is evidenced. [Color figure can be viewed in the online issue, which is available at www.wileyonlinelibrary.com]

epilepticus was reported as affected by neonatal-onset spasms and successive refractory focal seizures (Fig. 1).

\section{Patient 1}

Patient 1 was the first child of healthy unrelated parents, born at term, after an uneventful pregnancy and vacuum-assisted delivery. At birth weight was 2,380 g ( $<3 \mathrm{rd}$ centile), length was $47 \mathrm{~cm}$ (3rd centile), and head circumference was $31 \mathrm{~cm}$ (2nd centile). At age 20 days, especially at drowsiness, he presented clusters of spasms associated with erratic myoclonic jerks.

The EEG disclosed a suppression burst pattern compatible with OS (Fig. 2). Adrenocorticotropic hormone and vigabatrin were not effective. After the introduction of valproate, spasm frequency decreased but the EEG became hypsarrhythmic.

The growth parameters remained low during his development: at 6 months head circumference was $41 \mathrm{~cm}$ (2nd centile), weight
$6,500 \mathrm{~g}$ ( $3 \mathrm{rd}$ centile), and length $63 \mathrm{~cm}$ ( $3 \mathrm{rd}$ centile); at 12 months head circumference was $42 \mathrm{~cm}$ ( $<2$ nd centile), weight $9,300 \mathrm{~g}$ (10th centile), and length $72 \mathrm{~cm}$ (3rd centile) and now ( 22 months of age) he showed microcephaly (head circumference $42 \mathrm{~cm}$, $<2$ nd centile) and growth deficiency (weight 10,000 g, $<3$ rd centile, length $85 \mathrm{~cm}, 25$ th centile) without dysmorphic features, intellectual impairment, hypotonic tetraparesis with pyramidal signs, and requires gavage feeding. Physical examination did not reveal any genital anomaly and now penile stretched length is $3.5 \mathrm{~cm}$ (10-50th centile). Daily isolated spasms and focal seizures persist despite the therapy; the EEG is characterized by multifocal paroxysms. Metabolic tests [very long chain fatty acids (VLCFA), plasma and urinary aminoacids, carnitine, and acilcarnitine] showed normal results. Brain MRI performed at 6 months of age was normal, while at 22 months it showed diffuse brain atrophy. Standard karyotype and analysis of telomeric rearrangements were both normal. 


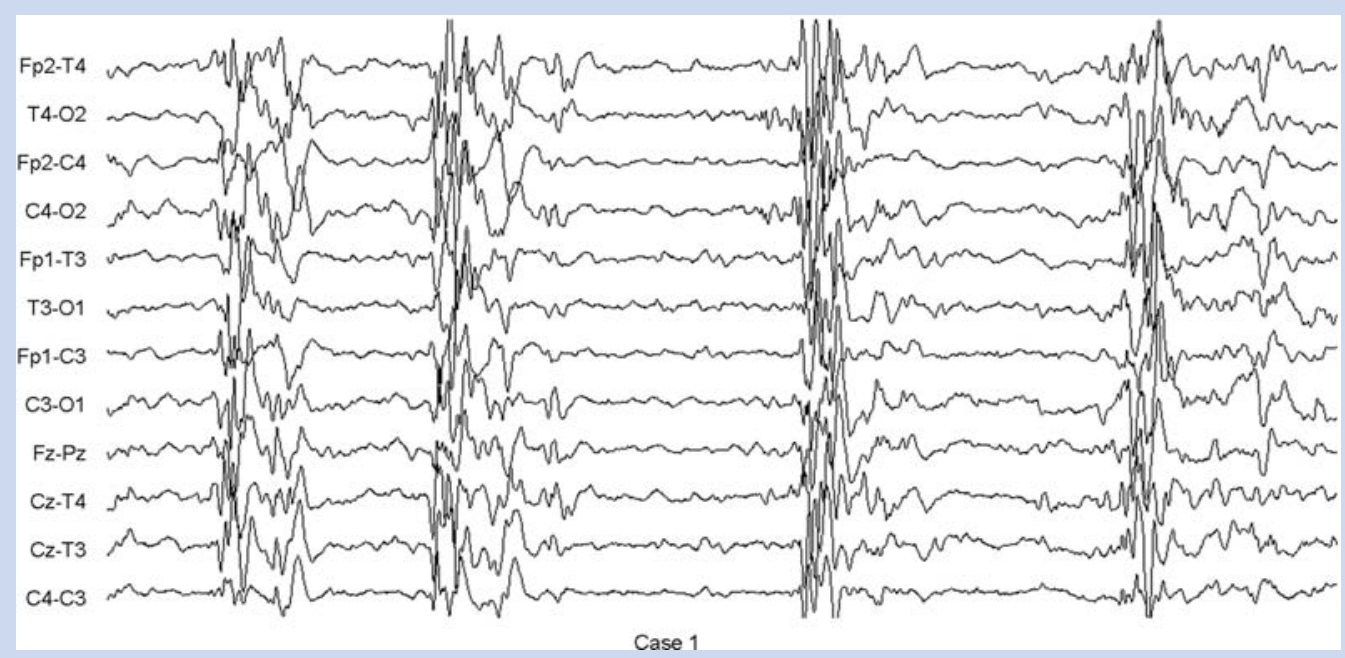

FIG. 2. EEG patient 1. At 1 month of age the child presents a suppression-burst pattern that is compatible with OS.

\section{Patient 2}

Patient 2 was the second child of nonconsanguineous parents. The father had benign childhood epilepsy. Pregnancy, delivery, weight $(3,200 \mathrm{~g})$, length $(51 \mathrm{~cm})$, and head circumference $(33 \mathrm{~cm})$ at birth were normal. Focal seizures, characterized by staring followed by right-side jerks and brief generalized clonic attacks, occurred at 6 days of life. EEG showed a suppression-burst pattern that was compatible with OS (Fig. 3). Vitamin B6, phenobarbital, and midazolam were used without success. At age 2 months, he presented with polymorphic focal motor seizures associated with spasms in clusters evolving into epileptic encephalopathy resistant to vigabatrin, phenytoin, adrenocorticotropic hormone. The EEG became hypsarrhythmic. Other treatments (lamotrigine, carbamazepine, clobazam, and valproate) did not change seizurefrequency. Postnatal development was within normal ranges since the age of 22 months, when he showed progressive deceleration of head circumference $(46.5 \mathrm{~cm}, 50 \mathrm{th}-2 \mathrm{nd}$ centile). At the age of 2 years, he had microcephaly (head circumference $46.5 \mathrm{~cm},<2$ nd centile; weight $10,400 \mathrm{~g}, 10$ th centile; length $87 \mathrm{~cm}, 50$ th centile) without dysmorphic features, intellectual impairment, and spastic tetraparesis requiring gavage feeding. No genital anomalies were found and penile stretched length was $4 \mathrm{~cm}$ (50th centile) at the age of 2 years. Results of several investigations (blood lactate and ammonium, plasma aminoacids, VLCFA, serum sialotransferrin isofocusing, purines and pyrimidines, sulfi-test, serum copper and ceruloplasmin, CSF analysis and dosage of neurotransmitters, urinary excretion of organic acids and aminoacids) were negative. Brain MRI at age 6 days was normal, and consecutive MRI at age 2 years revealed a slight diffuse brain atrophy. Standard karyotype was normal.

\section{Molecular analysis}

Regular informed consent for genetic testing was obtained from the parents of the two affected boys. Genomic DNA was extracted from peripheral blood leukocytes (PBL) with standard methods. Mutation analysis of the ARX gene was performed by PCR amplification and direct sequencing of fragments representing all the coding exons and intron-exon boundaries, with primers and conditions modified by Kato et al. [2004]. Direct sequencing of the amplification products was performed with the use of the BigDye ${ }^{\circledR}$ Terminator v3.1 Cycle Sequencing Kit (PE Applied Biosystems, Foster City, CA) on an ABI 3100 automated DNA sequencer (Applied Biosystems). The sequences obtained were compared with the reference $A R X$ sequence (GenBank accession number: NM_139058) by BLAST analysis. Total RNA was extracted from fresh peripheral blood using the Trizol procedure (Life Technologies, Grand Island, NY) and cDNA was obtained using the superscript first-strand system for RT-PCR, with the primers being selected by Primer Express software. Primers amplifying a product from exon 4 to exon 5, fw: 5'-CCAGCTTTCATCAGCCCGGC-3' and rev: 5'-GTGCTGGTGCCCGGCAGG-3' were designed for the missense mutation.

\section{RESULTS}

The mutation scanning performed allowed us to detect, in both individuals, the presence of a single base substitution at nucleotide 1604 of the ARX gene coding sequence (c.1604T >A: Ref. Seq. NM_139058), resulting in the substitution of the leucine residue at position 535 of the aminoacid sequence with a glutamine (p.Leu535Gln). The substitution has not been found in $150 \mathrm{X}$ chromosomes from the control population. The same mutation was present in the DNA of the two mothers, and maternal grandmother, while it was absent in the two unaffected maternal uncles. Moreover, linkage analysis (data not shown) with a panel of microsatellites, spanning the whole $\mathrm{X}$ chromosome excluded the disease causing involvement of other X chromosome loci. RT-PCR analysis evidenced the transcription of the mutant allele.

\section{DISCUSSION}

Both children presented with specific electroclinical features suggestive of OS subsequently evolving into a drug-resistant epileptic 


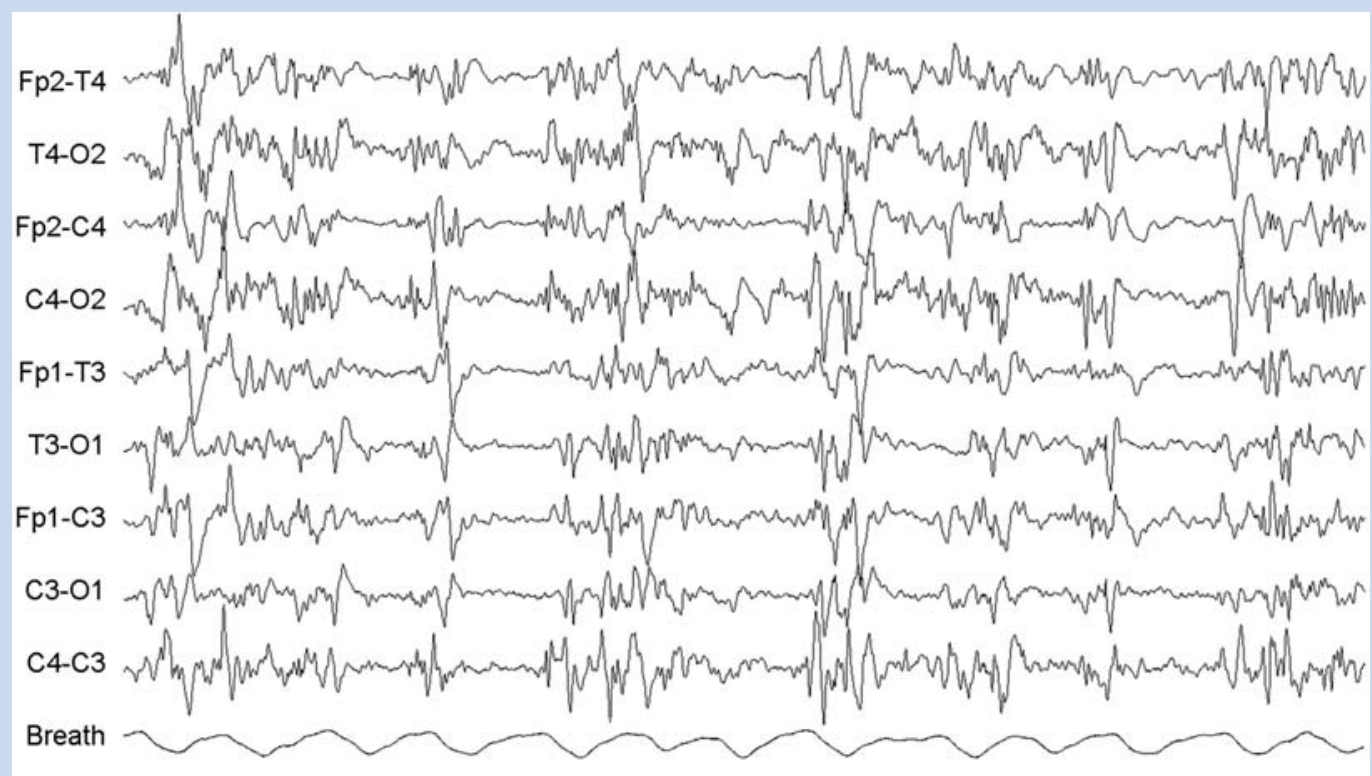

Caso 2

FIG. 3. EEG patient 2. At 6 days of age the child presents a suppression-burst pattern that is compatible with OS.

encephalopathy with spasms. The X-linked inheritance, suggested by the family history, is confirmed by the molecular results.

Besides both children show a clinical phenotype characterized by microcephaly without dysmorphic features and absence of genital anomalies, although patient one presented growth deficiency from birth, while Patient 2 showed normal auxological measures at birth and developed progressive microcephaly in the second year of life.

In both cases diffuse brain atrophy on MRI at 2 years of age could be related to the persistence of severe epileptic encephalopathy.

The electroclinical features of our subjects, except for the absence of genitalia malformations, are similar to those reported by Kato et al. [2007]. Recently, a novel $A R X$ gene mutation in male infant without genital anomalies, presenting with OS associated with a rapidly progressive and severe neurodegeneration with cortical atrophy, has been described [Absoud et al., 2010].

This confirms the possible causative relationship between $A R X$ gene mutations and OS. The molecular analysis of the $A R X$ gene revealed a missense mutation (c.1604T $>$ A) on the DNA of both affected boys, of their mothers and grand mother. This previously unreported mutation, not found in more than $100 \mathrm{X}$ chromosomes of the general population, is to be considered pathogenic. In fact it leads to a variation of the chemical characteristics of the aminoacid sequence by substituting the nonpolar hydrophobic leucine residue with a polar hydrophilic glutamine in the functionally relevant Aristaless domain (p.Leu535Gln) of the gene.

To further confirm the disease-causing nature of the detected variant, a multi-sequence alignment analysis was performed that showed a strong phylogenetic conservation of the specific leucine residue. The translation of the aberrant allele, as demonstrated by the cDNA analysis, excluded the occurrence of a nonsense mediated RNA decay suggesting that the presence of an aberrant protein, rather than its absence, is responsible for the disease. The absence of the mutation in the unaffected uncles further supports the segregation of the molecular defect with the disease.

Differently from sporadic OS cases [Kato et al., 2007; Absoud et al., 2010], the novel mutation of the $A R X$ gene we describe is found to segregate in a family, and consists in a missense mutation rather than in a longer expansion of the first polyalanine tract of the gene.

The similar clinical phenotypes, characterized by microcephaly without dysmorphic features and absence of genital anomalies, and electroclinical picture, suggestive of OS, presented in the patients we report on are important to better define the phenotype related to this novel $A R X$ gene mutation and to confirm the differentiation between a malformative and nonmalformative group, related to missense mutations outside the homeobox of the gene.

This report demonstrates the involvement of $A R X$ gene mutations other than longer polyalanine tract expansions, in the pathogenesis of cryptogenic epileptic encephalopathy with very early onset, such as OS. Our data suggests that the severity of the electroclinical picture (OS vs. West syndrome) in patients with $A R X$ mutations does not simply, or exclusively, correlate with the extent of expansions of the polyalanine tracts, but rather with the functional effect of different pathogenetic mutations.

Furthermore, while supporting the causative relationship between $A R X$ mutations and OS, our data strongly suggests the opportunity for searching for $A R X$ mutations in patients with sporadic or familial OS.

\section{REFERENCE}

Absoud M, Parr JR, Halliday D, Pretorius P, Zaiwalla Z, Jayawant S. 2010. A novel ARX phenotype: Rapid neurodegeneration with Ohtahara 
syndrome and a dyskinetic movement disorder. Dev Med Child Neurol 52:305-307.

Guerrini R, Moro F, Kato M, Barkovich AJ, Shiihara T, McShane MA, Hurst J, Loi M, Tohyama J, Norci V, Hayasaka K, Kang UJ, Das S, Dobyns WB. 2007. Expansion of the first Poly A tract of $A R X$ causes infantile spasms and status dystonicus. Neurology 69:427-433.

Kato M, Dobyns WB. 2005. X-linked lissencephaly with abnormal genitalia (XLAG) as a tangential migration disorder causing intractable epilepsy proposal for a new term "interneuronopathy." J Child Neurol 20:392-397.

Kato M, Das S, Petras K, Sawaishi Y, Dobyns WB. 2003. PolyAlanine expansion of ARX associated with cryptogenic West syndrome. Neurology 61:267-276.

Kato M, Das S, Petras K, Kitamura K, Morohashi K, Abuelo DN, Barr M, Bonneau D, Brady AF, Carpenter NJ, Cipero KL, Frisone F, Fukuda T, Guerrini R, Iida E, Itoh M, Feldman Lewanda A, Nanba Y, Oka A, Proud VK, Saugier-Veber P, Schelley SL, Selicorni A, Shaner R, Silengo M, Stewart F, Sugiyama N, Toyama J, Toutain A, Vargas AL, Yanazawa M, Zackai EH, Dobyns WB. 2004. Mutations of $A R X$ are associated with striking pleiotropy and consistent genotype-phenotype correlation. Hum Mutat 23:147-159.

Kato M, Saito S, Kamei A, Shiraishi H, Ueda Y, Akasaka M, Tohyama J, Akasaka N, Hayasaka K. 2007. A longer polyalanine expansion mutation in the $A R X$ gene causes early infantile epileptic encephalopathy with suppression-burst pattern (Ohtahara syndrome). Am J Hum Genet 81:361-366.

Poirier K, Eisermann M, Caubel I, Kaminska A, Peudonnier S, Boddaert N, Saillour Y, Dulac O, Souville I, Beldjord C, Lascelles K, Plouin P, Chelly J, Bahi-Buisson N. 2008. Combination of infantile spasms, non-epileptic seizures and complex movement disorder: A new case of ARX-related epilepsy. Epilepsy Res 80:224-228.

Stromme P, Mangelsdorf ME, Scheffer IE, Gecz J. 2002. Infantile spasms, dystonia, and other X-linked phenotypes caused by mutations in Aristaless related homeobox gene, ARX. Brain Dev 24:266-268.

Turner G, Partington M, Kerr B, Mangelsdorf M, Gecz J. 2002. Variable expression of mental retardation, autism, seizures, and dystonic hand movements in two families with an identical $A R X$ gene mutation. Am J Med Genet 112:405-411. 